www.jmscr.igmpublication.org

Impact Factor (SJIF): 6.379

Index Copernicus Value: 71.58

ISSN (e)-2347-176x ISSN (p) 2455-0450

crossref DOI:_https://dx.doi.org/10.18535/jmscr/v6i3.89

Journal Of Medical Science And Clinical Research

\title{
Prevalence of under-nutrition among children (1-5 years of age) and its association with various socio-demographic factors in Rohtak city, Haryana
}

\author{
Authors \\ Dr Brijesh Kumar ${ }^{1}$, Dr R.B.Jain ${ }^{2}$, Dr Gaurav Rajawat ${ }^{1}$, Dr J.P.Rajliwal ${ }^{1}$, \\ Dr Kashish Grover ${ }^{3}$, Dr Sandeep Sharma ${ }^{1}$ \\ ${ }^{1}$ Resident, Department of Community Medicine, PGIMS, Rohtak \\ ${ }^{2}$ Senior Professor, Department of Community Medicine, PGIMS, Rohtak \\ ${ }^{3}$ Senior Resident, Department of Community Medicine, PGIMS, Rohtak \\ Corresponding Author \\ Dr R.B.Jain \\ Senior Professor, Community Medicine, Pt B D Sharma, PGIMS, Rohtak \\ Email: rbjainpgims@gmail.com, Mobile: 9416267947
}

\begin{abstract}
Background: Under nutrition refers to a pathological state resulting from a relative or absolute deficiency of one or more essential nutrients. The term under nutrition encompasses wasting, stunting and underweight. As per National Family Health Survey IV (2015-16), prevalence of stunting, wasting and underweight among under-five children in India is 38.4\%, 21\% and 35.7\% respectively.

Methods: This cross-sectional study was conducted in an urban area of district Rohtak from July 2016 to June 2017 among 400 children (1-5 years of age) which were randomly selected from 14 anganwadi centers. The anthropometric measurement and nutritional status categorization among children was done using WHO guidelines.

Results: The prevalence of stunting, wasting and underweight to be $33.8 \%, 21.5 \%$ and $34.5 \%$ respectively. Under nutrition rates were found to be significantly higher in children whose mothers were illiterate, children belonging to SC category and children of lower and upper-lower socio-economic class.

Conclusion: It was revealed in this study that the prevalence of under nutrition was unacceptably high among the children. Every endeavor should be made to combat the under nutrition in children through multi-sectoral and multipronged approach.

Keywords: under nutrition, children, urban, nutrition.
\end{abstract}

\section{Introduction}

Nutrition is defined as science of food and its relationship to health. It is concerned mainly with the part played by nutrients in body growth, development and maintenance. ${ }^{1}$ Nutrition is a basic human need and a prerequisite to a healthy life. Undernutrition refers to a pathological state resulting from a relative or absolute deficiency of one or more essential nutrients. Undernutrition signifies an imbalance between the supply of calories and the body's demand for them to ensure optimal growth and function. ${ }^{2}$ The term 
undernutrition encompasses wasting, stunting and underweight. Wasting is inadequate weight for height and it reflects acute undernutrition. Stunting is inadequate height for age and it reflects chronic undernutrition. Underweight is inadequate weight for age and is a composite measure of stunting and wasting. It can result from either acute or chronic or both. It is well acknowledged that investment in human resource development is a prerequisite for any nation to progress. Children of today are citizens of tomorrow, and hence improving nutritional status of children becomes extremely important. Early childhood, that is the first six years constitutes the most crucial period in life, when the foundations are laid for cognitive, social and emotional language, physical/motor development and cumulative lifelong learning. ${ }^{3}$

The United Nations Children Fund (UNICEF) conceptual framework of the determinants of child undernutrition defines the multifactorial causality of undernutrition. Nutritional status is influenced by three broad factors i.e. food, health and care. Food, health and care are affected by social, economic and political factors. The combination and relative importance of these factors differ from country to country. ${ }^{4}$

Globally, prevalence of underweight, stunting and wasting among under-five children is $14.4 \%$, $22.9 \%$ and $7.7 \%$ respectively. ${ }^{5,6}$ One in every three malnourished children of the world lives in India. ${ }^{7}$ As per National Family Health Survey IV (2015-16), prevalence of stunting, wasting and underweight among under-five children in India is $38.4 \%, \quad 21 \%$ and $35.7 \%$ respectively (corresponding to $48 \%, 19.8 \%$ and $42.5 \%$ respectively in NFHS III).In Haryana as per National Family Health Survey IV, 34\%, 21.2\%, $29.4 \%$ and $9 \%$ of children below five years suffer from stunting, wasting, underweight and severe wasting respectively (corresponding figure for NFHS III was $45.7 \%, 19.1 \%, 39.6 \%$ and $5 \%$ respectively). ${ }^{8,9}$

\section{Aim and Objectives}

To estimate the prevalence of undernutrition among children (1-5 years) using anthropometric measurements and to determine the sociodemographic factors associated with undernutrition.

\section{Material and Methods \\ Study Area}

This study was carried out in urban field practice area of the Department of Community Medicine, Pt. B.D Sharma PGIMS, Rohtak. A total of 14 anganwadi centers were there under this area.

Study Design: descriptive study of cross-sectional design.

Study Period: July 2016 to June 2017.

Study Population: The study population consisted of children 1-5 years of age, registered at respective anganwadi centers and residing in the study area for more than six months, along with their mothers.

Sample Size Determination: In Haryana, the prevalence of underweight among under-five children was $29.4 \%$ (NFHS-4) ${ }^{29}$. The optimal sample size was 398 on the basis of $30 \%$ prevalence (approximate) of underweight children using the following formula, $\mathrm{n}=(1.96)^{2} \mathrm{p}(1-\mathrm{p}) / \mathrm{d}^{2}$, where $\mathrm{n}=$ sample size, $\mathrm{p}=$ prevalence, $\mathrm{d}=$ allowable error i.e. $15 \%$ of p. $[\mathrm{n}=$ $\left.(1.96)^{2} * 0.3 * 0.7 / 0.045^{2}\right]$. For the purpose of the study, a sample size of 400 subjects was taken.

\section{Exclusion Criteria}

1. Those children whose mothers were not willing to give consent.

2. Children with known congenital anomalies.

3. If the subject could not be contacted on three consecutive visits.

\section{Sampling Technique}

The total population of the study area, as per household survey conducted by MPHW with assistance of anganwadi workers, was 25077 (as on March 2015). A total of 14 anganwadi centers come under the area being served by the 3 Urban 
Health Posts. All the 14 anganwadi centers were selected for the study. From each selected anganwadi center, a list of 1-5 years of age children was prepared using anganwadi registers and 25 to 30 children were picked up from each anganwadi center, by simple random sampling (SRS) technique, to make a sample size of 400 .

\section{Data Collection}

A pre-designed, pre-tested and semi-structured interview schedule was used to collect information from the child's mother after taking informed consent. Weight of the children was measured by Salter's weighing scale with minimum clothing and without shoes. Height of the children was measured with the help of a non-flexible measuring tape, by making the child, after removing the shoes to stand on a flat surface with feet parallel and with heels, buttocks, shoulders and back of head touching the wall. The head was placed in Frankfurt's horizontal plane with arms hanging at sides in natural manner. The children were classified according to their nutritional status using WHO Child Growth Standards.

\section{Under nutrition Indices: ${ }^{10}$}

- Underweight: If Z-score of children for a given weight for age is less than -2 SD from median of the WHO Child Growth Standards.

- Stunting: If Z-score of children for a given height for age is less than -2 SD from median of the WHO Child Growth Standards.

- Wasting: If Z-score of children for a given weight for height is less than -2 SD from median of the WHO Child Growth Standards.

- Moderate undernutrition: If Z-score of children for a given weight for age or height for age or weight for height are in between -3 SD or below -2 SD of the median of the WHO Child Growth Standards.
- Severe undernutrition: If Z-score of children for a given weight for age or height for age or weight for height are below -3 SD of the median of the WHO Child Growth Standards.

\section{Data Analysis}

The data was entered in the MS EXEL spread sheet, coded appropriately and cleansed for any possible typing error and then the data was analysed by chi-square statistical test using SPSS 20 (Statistical package for social sciences) software as per study objective. If the $P$ value in Chi-square test was found $<0.05$ then the result was considered as significant.

\section{Results}

The present study was carried out in urban field practice area of the Department of Community Medicine, Pt. B.D Sharma PGIMS, Rohtak and a total of 14 anganwadi centers are there under this area. All the 14 anganwadi centers were selected for the study. A sample size of 400 children were selected from these anganwadi centers using simple random sampling.

The present study included $58.8 \%$ boys and $41.2 \%$ girls, $98.0 \%$ of children belonged to Hindu religion and only $2.0 \%$ belonged to Sikh religion. Out of all the children, $43.5 \%$ belonged to general caste while $34.2 \%$ and $22.3 \%$ belonged to OBC and SC category respectively. More than half of children belonged to nuclear family $(52.8 \%)$ and nearly two-thirds of children $(64.5 \%)$ belonged to families having family size up to 2 .

Nearly three-fourth of the mothers were literate and only $18.5 \%$ of mothers were working. More than half of children belonged to Lower-middle and Upper-lower class $(25.7 \%$ and $37.0 \%$ respectively) as per Modified Kuppuswamy scale for socioeconomic status. (table 1) 
Table 1: Distribution of children by Socio-demographic characteristics

\begin{tabular}{|c|c|c|}
\hline Characteristics & Frequency & Percentage \\
\hline \multicolumn{3}{|l|}{ Sex } \\
\hline Male & 235 & 58.8 \\
\hline Female & 165 & 41.2 \\
\hline \multicolumn{3}{|l|}{ Religion } \\
\hline Sikh & 8 & 2.0 \\
\hline \multicolumn{3}{|l|}{ Categorv } \\
\hline General & 174 & 43.5 \\
\hline OBC & 137 & 34.2 \\
\hline SC & 89 & 22.3 \\
\hline \multicolumn{3}{|l|}{ Type of family } \\
\hline Nuclear & 211 & 52.8 \\
\hline Joint & 135 & 33.7 \\
\hline $3^{\text {rd }}$ generation & 54 & 13.5 \\
\hline \multicolumn{3}{|l|}{ Family size } \\
\hline Up to 2 & 258 & 64.5 \\
\hline 3 or more & 142 & 35.5 \\
\hline \multicolumn{3}{|l|}{ Literacy status of mother } \\
\hline Illiterate & 96 & 24.0 \\
\hline Primary or middle school & 156 & 39.0 \\
\hline High school or senior secondary & 91 & 22.8 \\
\hline Graduate or diploma or above & 57 & 14.2 \\
\hline \multicolumn{3}{|l|}{ Occupation of mother } \\
\hline Housewife & 326 & 81.5 \\
\hline Working & 74 & 18.5 \\
\hline \multicolumn{3}{|c|}{ Socioeconomic status (Modified Kuppuswamy Scale) } \\
\hline Upper & 33 & 8.3 \\
\hline Upper-middle & 90 & 22.5 \\
\hline Lower-middle & 103 & 25.7 \\
\hline Upper-lower & 148 & 37.0 \\
\hline Lower & 26 & 6.5 \\
\hline
\end{tabular}

The prevalence of stunting was found to be $\mathbf{3 3 . 8 \%}$ (moderate stunting being $24.8 \%$ and severe wasting being 9.0\%), prevalence of wasting was $\mathbf{2 1 . 5 \%}$ (moderate wasting being $13.5 \%$ and severe wasting being $8.0 \%$ ) and prevalence of underweight was $\mathbf{3 4 . 5 \%}$ (moderate underweight being $25.3 \%$ and severe underweight being $9.2 \%$ ). (Table 2)

Table 2: Prevalence of undernutrition among children using WHO child growth standards

\begin{tabular}{|c|c|c|c|c|}
\hline \multirow[t]{2}{*}{ Characteristics } & Boys $(\mathrm{N}=235)$ & Girls (N=165) & Total $(\mathrm{N}=400)$ & \\
\hline & Frequency(\%) & Frequency $(\%)$ & Frequency $(\%)$ & \\
\hline \multicolumn{4}{|l|}{ Height for age } & \multirow{4}{*}{$\begin{array}{c}\chi^{2}=0.005 \mathrm{df}=2 \\
\mathbf{p}=0.997\end{array}$} \\
\hline No stunting & $156(66.4)$ & $109(66.1)$ & $265(66.2)$ & \\
\hline Moderate stunting & $58(24.7)$ & $41(24.8)$ & $99(24.8)$ & \\
\hline Severe stunting & $21(8.9)$ & $15(9.1)$ & $36(9.0)$ & \\
\hline \multicolumn{5}{|l|}{ Weight for height } \\
\hline No wasting & $185(78.7)$ & $129(78.2)$ & $314(78.5)$ & \multirow{3}{*}{$\begin{array}{c}\chi^{2}=0.049 \mathrm{df}=2 \\
p=0.976\end{array}$} \\
\hline Moderate wasting & $31(13.2)$ & $23(13.9)$ & $54(13.5)$ & \\
\hline Severe wasting & $19(8.1)$ & $13(7.9)$ & $32(8.0)$ & \\
\hline \multicolumn{5}{|l|}{ Weight for age } \\
\hline No underweight & $159(67.6)$ & $103(62.4)$ & $262(65.5)$ & \multirow{3}{*}{$\begin{array}{c}\chi^{2}=1.577 \mathrm{df}=2 \\
p=0.454\end{array}$} \\
\hline Moderate underweight & $54(23.0)$ & $47(28.5)$ & $101(25.3)$ & \\
\hline Severe underweight & $22(9.4)$ & $15(9.1)$ & $37(9.2)$ & \\
\hline
\end{tabular}


The present study showed that prevalence of stunting, wasting and underweight was higher in case of children belonging to SC category $(39.3 \%$,

Table 3: Association of nutritional status of children and caste-based categories

\begin{tabular}{|c|c|c|c|c|}
\hline & No Stunting(n=265) & Moderate $(n=99)$ & Severe $(n=36)$ & \\
\hline & Frequency $(\%)$ & Frequency $(\%)$ & Frequency (\%) & \\
\hline General $(n=174)$ & $116(66.7)$ & $43(24.7)$ & $15(8.6)$ & \multirow{3}{*}{$\begin{array}{c}\chi^{2}=13.674 \mathrm{df}=4 \\
p=0.008\end{array}$} \\
\hline OBC $(n=137)$ & $95(69.3)$ & $37(27.0)$ & $5(3.6)$ & \\
\hline \multirow[t]{2}{*}{ SC $(n=89)$} & $54(60.7)$ & $19(21.3)$ & $16(18.0)$ & \\
\hline & No wasting(n=314) & Moderate $(n=54)$ & Severe $(n=32)$ & \\
\hline General $(n=174)$ & $140(80.5)$ & $21(12.1)$ & $13(7.4)$ & \multirow{3}{*}{$\begin{array}{c}\chi^{2}=11.597 \mathrm{df}=4 \\
\mathrm{p}=0.021\end{array}$} \\
\hline OBC $(n=137)$ & $110(80.3)$ & $22(16.1)$ & $5(3.6)$ & \\
\hline \multirow[t]{2}{*}{$\mathrm{SC}(\mathrm{n}=89)$} & $64(71.9)$ & $11(12.4)$ & $14(15.7)$ & \\
\hline & $\begin{array}{c}\text { No } \\
\text { underweight }(n=262)\end{array}$ & Moderate $(n=101)$ & Severe $(n=37)$ & \\
\hline General $(n=174)$ & $116(66.7)$ & $42(24.1)$ & $16(9.2)$ & \multirow{3}{*}{$\begin{array}{c}\chi^{2}=14.970 \mathrm{df}=4 \\
p=0.005\end{array}$} \\
\hline OBC $(n=137)$ & $98(71.6)$ & $34(24.8)$ & $5(3.6)$ & \\
\hline $\mathrm{SC}(\mathrm{n}=89)$ & $48(53.9)$ & $25(28.1)$ & $16(18.0)$ & \\
\hline
\end{tabular}

The prevalence of stunting, wasting and underweight among children was found to be higher who had illiterate mothers $(41.6 \%, 28.1 \%$ and $52.1 \%$ respectively) and lowest in mothers

$28.1 \%$ and $46.1 \%$ respectively). This distribution was statistically significant. (Table 3)

Table 4: Association between nutritional status of children and education of mother

\begin{tabular}{|c|c|c|c|c|}
\hline & $\begin{array}{l}\text { No Stunting } \\
\quad(n=265)\end{array}$ & Moderate $(n=99)$ & Severe $(n=36)$ & \\
\hline Illiterate $(n=96)$ & $56(58.4)$ & $25(26.0)$ & $15(15.6)$ & \multirow{4}{*}{$\begin{array}{c}\chi^{2}=15.680 \mathrm{df}=6 \\
p=0.016\end{array}$} \\
\hline Primary/middle(n=156) & $101(64.7)$ & $47(30.2)$ & $8(5.1)$ & \\
\hline High/Sr. Sec.(n=91) & $63(69.2)$ & $18(19.8)$ & $10(11.0)$ & \\
\hline \multirow[t]{2}{*}{ Grad./dip./above(n=57) } & $45(78.9)$ & $9(15.8)$ & $3(5.3)$ & \\
\hline & $\begin{array}{c}\text { No } \\
\text { wasting(n=314) }\end{array}$ & Moderate $(n=54)$ & Severe $(n=32)$ & \\
\hline Illiterate $(n=96)$ & $69(71.9)$ & $13(13.5)$ & $14(14.6)$ & \multirow{4}{*}{$\begin{array}{c}\chi^{2}=15.084 \mathrm{df}=6 \\
p=0.020\end{array}$} \\
\hline Primary/middle(n=156) & $125(80.2)$ & $25(16.0)$ & $6(3.8)$ & \\
\hline High/Sr.Sec.(n=91) & $69(75.8)$ & $12(13.2)$ & $10(11.0)$ & \\
\hline \multirow[t]{2}{*}{ Grad./dip./above(n=57) } & $51(89.5)$ & $4(7.0)$ & $2(3.5)$ & \\
\hline & $\begin{array}{c}\text { No underweight } \\
(n=262)\end{array}$ & $\operatorname{Moderate}(n=101)$ & Severe $(n=37)$ & \\
\hline Illiterate $(n=96)$ & $46(47.9)$ & $34(35.4)$ & $16(16.7)$ & \multirow{4}{*}{$\begin{array}{c}\chi^{2}=26.903 \mathrm{df}=6 \\
p=0.000\end{array}$} \\
\hline Primary/middle(n=156) & $104(66.7)$ & $44(28.2)$ & $8(5.1)$ & \\
\hline High/Sr.Sec. $(n=91)$ & $67(73.6)$ & $14(15.4)$ & $10(11.0)$ & \\
\hline Grad./dip./above(n=57) & $45(78.9)$ & $9(15.8)$ & $3(5.3)$ & \\
\hline
\end{tabular}


The prevalence of stunting, wasting and underweight was found to be higher in children of working mothers $(40.5 \%, 24.3 \%, 39.2 \%$ respectively) as compared to children whose

Table 5: Association between nutritional status of children and occupation of mother

\begin{tabular}{|c|c|c|c|c|}
\hline & No Stunting $(n=265)$ & Moderate (n=99) & Severe $(n=36)$ & \\
\hline Housewife $(n=326)$ & $221(67.8)$ & $77(23.6)$ & $28(8.6)$ & \multirow{2}{*}{$\begin{array}{c}\chi^{2}=1.873 \mathrm{df}=2 \\
p=0.392\end{array}$} \\
\hline \multirow[t]{2}{*}{ Working $(n=74)$} & $44(59.5)$ & $22(29.7)$ & $8(10.8)$ & \\
\hline & No wasting $(n=314)$ & Moderate $(n=54)$ & Severe $(n=32)$ & \\
\hline Housewife $(n=326)$ & $258(79.1)$ & $43(13.2)$ & $25(7.7)$ & \multirow{2}{*}{$\begin{array}{c}\chi^{2}=0.459 \mathrm{df}=2 \\
\mathbf{p}=0.795\end{array}$} \\
\hline \multirow{2}{*}{ Working $(\mathrm{n}=74)$} & $56(75.7)$ & $11(14.9)$ & $7(9.4)$ & \\
\hline & $\begin{array}{c}\text { No underweight } \\
(n=262)\end{array}$ & Moderate $(n=101)$ & Severe $(n=37)$ & \\
\hline Housewife $(n=326)$ & $217(66.6)$ & $80(24.5)$ & $29(8.9)$ & \multirow{2}{*}{$\begin{array}{c}\chi^{2}=0.896 \mathrm{df}=2 \\
p=0.639\end{array}$} \\
\hline Working $(n=74)$ & $45(60.8)$ & $21(28.4)$ & $8(10.8)$ & \\
\hline
\end{tabular}

The prevalence of stunting and underweight was found to be higher in children belonging to joint family $(36.3 \%$ and $35.6 \%$ respectively) and prevalence of wasting was higher in children

Table 6: Association between nutritional status of children and type of family

\begin{tabular}{|c|c|c|c|c|}
\hline & No Stunting $(n=265)$ & Moderate(n=99) & Severe $(n=36)$ & \\
\hline Nuclear $(n=211)$ & $138(65.4)$ & $55(26.1)$ & $18(8.5)$ & \multirow{3}{*}{\begin{tabular}{l}
$\chi^{2}=6.857 \mathrm{df}$ \\
$=4 \quad p=$ \\
\multicolumn{0}{c}{$\quad \mathrm{p}=$}
\end{tabular}} \\
\hline Joint $(n=135)$ & $86(63.7)$ & $38(28.1)$ & $11(8.2)$ & \\
\hline \multirow[t]{2}{*}{$3^{\text {rd }}$ gen. $(n=54)$} & $41(75.9)$ & $6(11.1)$ & $7(13.0)$ & \\
\hline & No wasting $(n=314)$ & Moderate(n=54) & Severe $(n=32)$ & \\
\hline Nuclear $(n=211)$ & $165(78.2)$ & $29(13.7)$ & $17(8.1)$ & \multirow{3}{*}{$\begin{array}{l}\chi^{2}=2.181 \mathrm{df} \\
=4 \underset{0.703}{p=}\end{array}$} \\
\hline Joint $(n=135)$ & $110(81.5)$ & $15(11.1)$ & $10(7.4)$ & \\
\hline \multirow[t]{2}{*}{$3^{\text {rd }}$ gen. $(n=54)$} & $39(72.2)$ & $10(18.5)$ & $5(9.3)$ & \\
\hline & $\begin{array}{c}\text { No } \\
\text { underweight }(n=262)\end{array}$ & Moderate(n=101) & Severe $(n=37)$ & \\
\hline Nuclear $(n=211)$ & $138(65.4)$ & $55(26.1)$ & $18(8.5)$ & \multirow{3}{*}{$\begin{array}{l}\chi^{2}=2.172 \text { df } \\
=4 \underset{0.704}{p=}\end{array}$} \\
\hline Joint $(n=135)$ & $87(64.4)$ & $36(26.7)$ & $12(8.9)$ & \\
\hline $3^{\text {rd }}$ gen. $(n=54)$ & $37(68.5)$ & $10(18.5)$ & $7(13.0)$ & \\
\hline
\end{tabular}

The prevalence of stunting, wasting and underweight was found to be highest in children belonging to lower class SES $(57.7 \%, 53.8 \%$ and $65.4 \%$ respectively), followed by children belonging to $3^{\text {rd }}$ generation family $(27.8 \%)$. But this distribution was not found to be statistically significant for any of the three prevalence rates. (Table 6) mothers were housewives $(32.2 \%, 20.9 \%$ and $33.4 \%$ respectively) but this difference was not found to be statistically significant. (Table 5) belonging to upper-lower class SES (48.0\%, $30.4 \%$ and $51.3 \%$ respectively). This distribution was found to be statistically significant. (Table 7) 
Table 7: Association between nutritional status of children and socioeconomic status (Modified Kuppuswamy Scale)

\begin{tabular}{|c|c|c|c|c|}
\hline & No & Moderate(n=99) & Severe $(n=36)$ & \\
\hline Upper (n=33) & $29(87.9)$ & $4(12.1)$ & $0(0.0)$ & \multirow{5}{*}{$\begin{array}{c}\chi^{2}=61.989 \mathrm{df}= \\
8 \quad p= \\
0.000\end{array}$} \\
\hline Upper-middle (n=90) & $79(87.8)$ & $10(11.1)$ & $1(1.1)$ & \\
\hline Lower-middle (n=103) & $69(67.0)$ & $27(26.2)$ & $7(6.8)$ & \\
\hline Upper-lower (n=148) & $77(52.0)$ & $52(35.2)$ & $19(12.8)$ & \\
\hline \multirow[t]{2}{*}{ Lower $(n=26)$} & $11(42.3)$ & $6(23.1)$ & $9(34.6)$ & \\
\hline & No wasting $(n=314)$ & Moderate(n=54) & Severe $(n=32)$ & \\
\hline Upper $(n=33)$ & $32(97.0)$ & $1(3.0)$ & $0(0.0)$ & \multirow{5}{*}{$\begin{array}{c}\chi^{2}=49.418 \mathrm{df}= \\
8 \quad p= \\
0.000\end{array}$} \\
\hline Upper-middle (n=90) & $83(92.2)$ & $7(7.8)$ & $0(0.0)$ & \\
\hline Lower-middle (n=103) & $84(81.5)$ & $14(13.6)$ & $5(4.9)$ & \\
\hline Upper-lower (n=148) & $103(69.6)$ & $26(17.6)$ & $19(12.8)$ & \\
\hline \multirow[t]{2}{*}{ Lower $(n=26)$} & $12(46.2)$ & $6(23.1)$ & $8(30.7)$ & \\
\hline & $\begin{array}{c}\text { No underweight } \\
(n=262)\end{array}$ & Moderate $(n=101)$ & Severe $(n=37)$ & \\
\hline Upper $(n=33)$ & $31(93.9)$ & $2(6.1)$ & $0(0.0)$ & \multirow{5}{*}{$\begin{array}{c}\chi^{2}=82.372 \mathrm{df}= \\
8 \quad p= \\
0.000\end{array}$} \\
\hline Upper-middle (n=90) & $83(92.2)$ & $5(5.6)$ & $2(2.2)$ & \\
\hline Lower-middle $(\mathrm{n}=103)$ & $67(65.0)$ & $29(28.2)$ & $7(6.8)$ & \\
\hline Upper-lower $(n=148)$ & $72(48.7)$ & $57(38.5)$ & $19(12.8)$ & \\
\hline Lower $(n=26)$ & $9(34.6)$ & $8(30.8)$ & $9(34.6)$ & \\
\hline
\end{tabular}

The prevalence of stunting, wasting and underweight was found to be higher in children belonging to families having family size 3 or more $(37.3 \%, 25.4 \%$ and $37.3 \%$ respectively) as compared to children belonging to family having family size up to 2 (31.8\%, $19.4 \%$ and $32.9 \%$ respectively) but this difference was not found to be statistically significant. (Table 8)

Table 8: Association between nutritional status of children and family size

\begin{tabular}{|c|c|c|c|c|}
\hline & No Stunting $(n=265)$ & Moderate (n=99) & Severe $(n=36)$ & \\
\hline Up to $2(n=258)$ & $176(68.2)$ & $61(23.7)$ & $21(8.1)$ & \multirow{2}{*}{$\begin{array}{c}\chi^{2}=1.382 \mathrm{df}=2 \\
\mathbf{p}=0.501\end{array}$} \\
\hline 3 or more $(n=142)$ & $89(62.7)$ & $38(26.8)$ & $15(10.5)$ & \\
\hline & No wasting $(n=314)$ & Moderate $(n=54)$ & Severe $(n=32)$ & \\
\hline Up to $2(n=258)$ & $208(80.6)$ & $32(12.4)$ & $18(7.0)$ & \multirow[t]{2}{*}{$\begin{array}{c}\chi^{2}=2.015 \mathrm{df}=2 \\
p=0.365\end{array}$} \\
\hline 3 or more $(n=142)$ & $106(74.6)$ & $22(15.5)$ & $14(9.9)$ & \\
\hline & $\begin{array}{l}\text { No underweight } \\
\qquad(n=262)\end{array}$ & Moderate $(n=101)$ & Severe $(n=37)$ & \\
\hline Up to $2(n=258)$ & $173(67.1)$ & $64(24.8)$ & $21(8.1)$ & \multirow{2}{*}{$\begin{array}{c}\chi^{2}=1.294 \mathrm{df}=2 \\
p=0.524\end{array}$} \\
\hline 3 or more $(n=142)$ & $89(62.7)$ & $37(26.1)$ & $16(11.2)$ & \\
\hline
\end{tabular}

\section{Discussion}

Prevalence of stunting in the present study was found to be $33.8 \%$ which was comparable with the studies of NFHS-4 (2015-16, Haryana) ${ }^{9}$ (33.4\%) and DLHS-4 (2012-13, Haryana) ${ }^{11}(31.8 \%)$. The prevalence of wasting was found to be $21.5 \%$.
Similar findings were observed in NFHS-4 (201516, Haryana) ${ }^{9}(21.0 \%)$ but prevalence of wasting was found higher in DLHS-4 (2012-13,

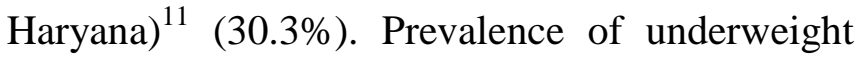
was found to be $34.5 \%$ which was similar as found in DLHS-4 (2012-13, Haryana) ${ }^{11}$ (32.9\%) 
but was higher as compared in NFHS-4 (2015-16, Haryana $)^{9}(28.5 \%)$.

Undernutrition rates were slightly higher among girls than the boys in the study. This difference might be due to presence of gender bias towards girls in the community. Similar results were found in the studies conducted by Yadav et al (2016, Haryana) $^{12}$ in which prevalence of underweight among girls and boys was $42.9 \%$ and $41.3 \%$ respectively and Ashok et al (2015, Karnataka) ${ }^{13}$ in which prevalence of stunting, wasting and underweight among girls was $42.2 \%, 13.3 \%$ and $32.1 \%$ respectively and among boys, it was $42.1 \%, 15.1 \%$ and $30.5 \%$ respectively.

Prevalence of stunting, wasting and underweight was found to be higher in case of children belonging to SC category $(39.3 \%, 28.1 \%$ and $46.1 \%$ respectively). The higher prevalence of undernutrition in the above mentioned social class might be due to poor socioeconomic conditions leading onto less awareness regarding food requirements among mothers belonging to this social class. Similar results were observed in the studies conducted by Sarkar (2016, West Bengal $)^{14}$, Meshram et al (2016, Gujarat $)^{15}$ and Pant et al (2013, Uttar Pradesh) ${ }^{16}$. Prevalence of stunting, wasting and underweight was found to be highest in children belonging to lower class SES (57.7\%, 53.8\% and $65.4 \%$ respectively), followed by children belonging to upper-lower class SES $(48.0 \%, \quad 30.4 \%$ and $51.3 \%$ respectively). The literacy status, food habits and awareness about food requirements along with poor environmental conditions were the factors that might be responsible for these findings. Similar results were reported in the studies of Yadav et al (2016, Haryana) $)^{12}$, Purohit et al (2017,

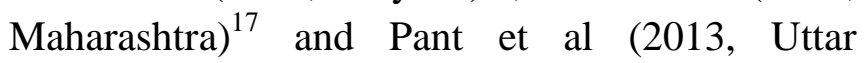
Pradesh $)^{16}$. Prevalence of stunting, wasting and underweight was found to be highest among children whose mothers were illiterate $(41.6 \%$, $28.1 \%$ and $52.1 \%$ respectively). The higher education of mothers increased their awareness about the nutritional needs of children and enhanced their capability to adequately look after their nutritional and health needs. Similar results were reported in the studies of Purohit et al (2017, Maharashtra) $^{17}$ and Pant et al (2013, Uttar Pradesh) ${ }^{16}$. Prevalence of stunting, wasting and underweight was found to be higher in children of working mothers $(40.5 \%, 24.3 \%, 39.2 \%$ respectively). The study conducted by Damor et al (2013, Gujarat) ${ }^{18}$ showed similar findings in which, prevalence of undernutrition was higher in the children of working mothers (57.8\%). This might be due to lack of time for adequate care and feeding practices among working mothers.

Prevalence of stunting and underweight was found to be higher in children belonging to joint family (36.3\% and $35.6 \%$ respectively) and prevalence of wasting was higher in children belonging to $3^{\text {rd }}$ generation family $(27.8 \%)$. This difference might be due to the reason that in joint families, less attention is given towards younger children for feeding them and their food requirements. Similar findings were observed in the studies conducted by Sengupta et al (2010, Punjab) ${ }^{19}$, Purohit et al (2017, Maharashtra) ${ }^{17}$ and Mamulwar et al (2014, Maharashtra $)^{20}$. Prevalence of undernutrition was increasing with the family size i.e. family size of 3 or more had higher prevalence of stunting, wasting and underweight $(37.3 \%, 25.4 \%$ and $37.3 \%$ respectively). This might be due to less attention given to individual child by mother in a family with increased family size. Similar results were obtained in the studies conducted by Ashok et al (2015, Karnataka) ${ }^{13}$, Meshram et al (2016, Gujarat $^{15}$ and Bhavsar et al (2012, Maharashtra $)^{21}$.

\section{Limitation}

In the present study, children aged 1-5 years were included to improve the participation of study subjects and reduce non-response rate, as participation of recently delivered mothers including infants in the study was difficult.

\section{Conclusion and Recommendation}

It is the health status of children that represents the overall health status of the people of country. 
Since this growing generation is going to be the future working citizens of the country, they should be healthy enough to make use of the full potential of their productive age.

It was revealed in this study that the prevalence of undernutrition was unacceptably high among the children. Every endeavor should be made to combat the undernutrition in children through multi-sectoral and multipronged approach such as nutritional education of mothers, growth monitoring, nutritional supplementation, nutritional rehabilitation and early diagnosis and treatment of morbidity besides providing environment conducive to health. A collective attempt by the government, non-governmental organizations and the community is crucial to decrease the load of undernutrition among children. There is urgent need for strengthening of the existing public health interventions and programs to tackle this problem ofunder nutrition amongst the most vulnerable population of our country.

Conflict of interest: None declared

\section{References}

1. Park K. Parks Textbook of Preventive and Social Medicine. $24^{\text {th }}$ ed. Jabalpur: Banarsidas Bhanot; 2017. p. 646-78.

2. Katsilambros N. Clinical Nutrition in Practice. $8^{\text {th }}$ ed. New York: John Wiley \&Sons; 2011. p. 37.

3. Government of India. Children in India 2012- A Statistical Appraisal [Internet]. New Delhi: Ministry of Statistics and Programme Implementation, Government of India; September 2012 [cited on 2017 Aug 17]. Available from: http://mospi.nic.in/sites/default/files/public ation_reports/Children_in_India_2012rev.pdf

4. United Nations Children's Fund. Improving child nutrition: The achievable imperative for global progress [Internet]. New York: UNICEF; 2013[Cited 2017

\section{Aug}

18].

Available

from:

https://www.unicef.org/gambia/Improving _Child_Nutrition_-

_the_achievable_imperative_for_global_pr ogress.pdf

5. World Bank. Prevalence of underweight, weight for age[Internet]. Washington DC: The World Bank; 2017 [Cited 2017 Aug 18]. Available from: https://data.worldbank.org/indicator/SH.S TA.MALN.ZS

6. Levels and Trends in Child Malnutrition: Joint child malnutrition estimates by UNICEF, WHO and World Bank Group [Internet]. Geneva: WHO; 2017 [Cited 2017 Aug 18]. Available from: https://data.unicef.org/resources/jointchild-malnutrition-estimates-2017-edition/

7. United Nation International Children's Emergency Fund. The State of the World's Children[Internet]. New York: UNICEF; 2016 [Cited 2017 Aug 18]. Available from: http://www.unicef.org/sowc/

8. International Institute for Population Sciences. National Family Health Survey4 (2015-16) - India Fact Sheet [Internet]. Mumbai: Ministry of Health and Family Welfare, Government of India; 2016 [Cited 2017 Aug 21]. Available from: http://rchiips.org/NFHS/pdf/NFHS4/India. pdf

9. International Institute for Population Sciences. National Family Health Survey4 (2015-16) - Haryana Fact Sheet [Internet]. Mumbai: Ministry of Health and Family Welfare, Government of India; 2016 [Cited 2017 Aug 21].Available from: http://rchiips.org/NFHS/pdf/NFHS4/HR_F actSheet.pdf

10. WHO Multicentre Growth Reference Study Group. WHO Child Growth Standards: Length/Height-for-age, weightfor-age, weight-for-length, weight-forheight and body mass index-for-age; Methods and development [Internet]. 
Geneva: World Health Organization; 2006 [Cited 2017 Aug 22]. Available from: http://www.who.int/childgrowth/standards/ technical_report/en/

11. International Institute for Population Sciences. District Level Household and Facility Survey-4 (2012-13) - Haryana Fact Sheet [Internet]. Mumbai: Ministry of Health and Family Welfare, Government of India; 2013 [Cited 2017 Aug27]. Available

from:http://rchiips.org/pdf/dlhs4/report/HR .pdf

12. Yadav SS, Yadav ST, Mishra P, Mittal A, Kumar R, Singh J. An epidemiological study of malnutrition among under five children of rural and urban Haryana. J Clin Diagn Res.2016;10(2):7-10.

13. Ashok NC, Santosh KA, Raghavendraswamy K, Sunil KD, Murali D, Chandrashekar SV. PEM in relation to birth order and birth interval in children aged 1-6 years in urban slums of Mysore city. Indian Journal of Public Health Research \& Development. 2015;6(1):30913.

14. Sarkar S. Cross-sectional study of child malnutrition and associated risk factors among children aged under five in West Bengal, India. International Journal of Population Studies. 2016;2(1):89-102.

15. Meshram II, Rao KM, Reddy CG, Sharad KS, Sreerama KK, Hari KR, et al. Prevalence of under nutrition and its predictors among under 5 yearchildren inSurat region, Gujarat, India. Journal of Clinical Nutrition \& Dietetics. 2016;2:112.

16. Pant B, Vaish A, Jain S, Ahmad S, Varshney AM, Rupesh. Malnutrition among under five children in the peri urban area of Meerut city: Impact of sociodemographic factors. Asian Journal of Pharmaceutical and Health Sciences. 2013;3(2):769-73.
17. Purohit L, Sahu P, Godale LB. Nutritional status of under- five children in a city of Maharashtra:a community based study. Int J Community Med Public Health. 2017;4(4):1171-1178.

18. Damor RD, Pithadia PR, Lodhiya KK, Mehta JP, Yadav SB. A study on assessment of nutritional and immunization status of under-five children in urban slums of Jamnagar city, Gujarat. Healthline Journal. 2013;4:35-9.

19. Sengupta P, Philip N, Benjamin AI. Epidemiological correlates of undernutrition in under-five year children in an urban slum of Ludhiana. Health Popul Perspect Issues. 2010;33:111-9.

20. Mamulwar MS, Rathod HK, Jethani S, Dhone A, Bakshi T, Lanjewar B, et al. Nutritional status of under-five childrenin urban slums of Pune. Int $\mathrm{J}$ Med Public Health. 2014;4(3):247-50.

21. Bhavsar S, Mahajan H, Kulkarni R. Maternal and environmental factors affecting the nutritional status of children in Mumbai urban slum. International Journal of Scientific and Research Publications.2012;2:111-6. 